\title{
Maternal early pregnancy vitamin D status in relation to fetal and neonatal growth: results of the multi-ethnic Amsterdam Born Children and their Development cohort
}

\author{
Evelien R. Leffelaar ${ }^{1,2}$, Tanja G. M. Vrijkotte ${ }^{3}$ and Manon van Eijsden ${ }^{2} *$ \\ ${ }^{1}$ Institute of Health Sciences, VU University Amsterdam, De Boelelaan 1085, 1081 HV Amsterdam, The Netherlands \\ ${ }^{2}$ Department of Epidemiology, Documentation and Health Promotion, Public Health Service of Amsterdam, PO Box 2200, \\ 1000 CE Amsterdam, The Netherlands \\ ${ }^{3}$ Department of Social Medicine, Academic Medical Centre, PO Box 22700, 1100 DE Amsterdam, The Netherlands
}

(Received 11 September 2009 - Revised 6 January 2010 - Accepted 12 January 2010 - First published online 2 March 2010)

Low vitamin D levels during pregnancy may account for reduced fetal growth and for altered neonatal development. The present study explored the association between maternal vitamin D status measured early in pregnancy and birth weight, prevalence of small-for-gestational-age (SGA) infants and postnatal growth (weight and length), as well as the potential role of vitamin D status in explaining ethnic disparities in these outcomes. Data were derived from a large multi-ethnic cohort in The Netherlands (Amsterdam Born Children and their Development (ABCD) cohort), and included 3730 women with live-born singleton term deliveries. Maternal serum vitamin D was measured during early pregnancy (median 13 weeks, interquartile range: $12-14)$, and was labelled 'deficient' ( $\leq 29.9 \mathrm{nmol} / \mathrm{l})$, 'insufficient' $(30-49.9 \mathrm{nmol} / \mathrm{l})$ or 'adequate' ( $\geq 50 \mathrm{nmol} / \mathrm{l})$. Six ethnic groups were distinguished: Dutch, Surinamese, Turkish, Moroccan, other non-Western and other Western. Associations with neonatal outcomes were analysed using multivariate regression analyses. Results showed that compared with women with adequate vitamin D levels, women with deficient vitamin D levels had infants with lower birth weights $(-114.4 \mathrm{~g}, 95 \% \mathrm{CI}-151 \cdot 2,-77 \cdot 6)$ and a higher risk of SGA (OR 2.4, $95 \%$ CI 1.9, 3.2). Neonates born to mothers with a deficient vitamin D status showed accelerated growth in weight and length during the first year of life. Although a deficient vitamin D status influenced birth weight, SGA risk and neonatal growth, it played a limited role in explaining ethnic differences. Although vitamin D supplementation might be beneficial to those at risk of a deficient vitamin D status, more research is needed before a nationwide policy on the subject can be justified.

\section{5-Hydroxyvitamin D: Ethnicity: Birth weight: Neonatal growth: ABCD Study}

The developmental origins of disease hypothesis states that many health outcomes in adult life are predetermined by the intra-uterine environment and fetal development. Numerous studies have shown an association between low birth weight and $\mathrm{CHD}$, altered glucose tolerance and raised blood pressure ${ }^{(1)}$. Also, there is evidence of an association between the rate of weight gain after infancy and heart disease in later life ${ }^{(1)}$.

Maternal nutritional status plays a crucial role in creating an optimal intra-uterine environment, and could therefore be a key factor in preventing adverse health outcomes later in life that are determined during fetal development. One important vitamin now recognised to be a possible influential component in this regard is vitamin D. Vitamin D, or calciferol, is essential for $\mathrm{Ca}$ homeostasis and bone mineralisation, and therefore vital to fetal and infant development ${ }^{(2)}$. Although there appears to be no consensus on the trimester in which vitamin $\mathrm{D}$ is most relevant, evidence suggests a role of vitamin $\mathrm{D}$ from early pregnancy onwards: even if the third trimester is the trimester with the most rapid growth, the trajectory is thought to be set early in gestation already ${ }^{(3,4)}$, at which stage also bone development starts ${ }^{(5,6)}$.

In accordance with the developmental origins of disease hypothesis, Cooper et al. ${ }^{(7)}$ and Pawley \& Bishop ${ }^{(8)}$ found an association between maternal vitamin D deficiency and several adverse health outcomes for pregnant women and their infants, such as lower maternal weight gain and reduced bone mineral acquisition during intra-uterine and early postnatal life. Furthermore, Scholl \& $\operatorname{Chen}^{(9)}$ showed that total maternal intake of vitamin $\mathrm{D}$ was associated with increased infant birth weight, and in a study by Brooke et al. ${ }^{(10)}$, more small-for-gestational-age (SGA) infants were born in a placebo-treated group (29\%) than in a vitamin D-supplemented group $(15 \%)$. To our knowledge, only Brooke et al. ${ }^{(11)}$ have investigated the relationship between

\footnotetext{
Abbreviations: 25(OH)D, 25-hydroxyvitamin D; ABCD, Amsterdam Born Children and their Development; SDS, standard deviation scores; SGA, smallfor-gestational-age; YHC, youth health care.

* Corresponding author: Dr Manon van Eijsden, fax + 3120 5555160, email mveijsden@ggd.amsterdam.nl

The work was performed at the Department of Epidemiology, Documentation and Health Promotion. Public Health Service of Amsterdam, PO Box 2200, 1000 CE Amsterdam, The Netherlands.
} 
maternal vitamin D status and postnatal growth. They reported significantly higher weights during the first year of life for children whose mothers received vitamin D supplementation.

A substantial amount of research shows that vitamin D deficiency is common among ethnic minorities in northern countries $^{(12-14)}$. Large deficiencies are most often reported for Turkish and Moroccan women, with 55-84\% of them having vitamin $\mathrm{D}$ deficiency ${ }^{(13,14)}$. These numbers are much higher than the $5-8 \%$ of Western women with vitamin D deficiency ${ }^{(13,14)}$. The reason for this difference in vitamin D status between native and immigrant populations may be the northern latitude of about $51^{\circ}$, where sun radiation results in vitamin D synthesis only from April to September. Vitamin D synthesis is restricted when combined with the stronger pigmentation in people from certain ethnic minorities when compared with the native population, because dark-skinned people need more sun exposure to produce the same amount of vitamin $\mathrm{D}^{(15-17)}$. Moreover, women from ethnic minorities often wear veils, which restricts their exposure to the sun even more ${ }^{(18,19)}$.

These vitamin $\mathrm{D}$ differences can be relevant in explaining the large disparities in neonatal measures found between ethnic groups. Neonates of non-Western origin often have lower birth weights, and are more likely to be $\mathrm{SGA}^{(20-22)}$. Ethnic differences have also been found in infant weight gain during the first 9 months of life ${ }^{(23-26)}$.

The present study set out to explore the association between maternal vitamin D status measured early in pregnancy and birth weight and infant growth, and its potential to explain disparities in these outcomes between different ethnic groups living in The Netherlands.

\section{Methods}

\section{Study population and design}

The Amsterdam Born Children and their Development (ABCD) study is a large prospective community-based cohort study that examines the relationship between maternal lifestyle and psychosocial conditions during pregnancy and the child's health at birth and in later life. The essentials of the study design have been described previously ${ }^{(27,28)}$. In brief, between January 2003 and March 2004, all pregnant women in Amsterdam were asked to take part in the ABCD study during their first prenatal visit to participating obstetric care providers (about the twelfth week of gestation). They were requested to complete a questionnaire that covered socio-demographic data, obstetric history, lifestyle, dietary habits and psychosocial factors. In addition, women were invited to participate in the ABCD biomarker study. For this study, an extra blood sample was taken during routine blood collection following the first prenatal check-up. Of the 12373 pregnant women invited to participate, 8266 returned the pregnancy questionnaire (response rate, 67\%). Of these respondents, 4389 women $(53 \%)$ participated in the biomarker study. Reliable serum vitamin D was measured in 4236 of these women (Fig. 1).

Data on infant weight and length were retrieved from the youth health care (YHC) centres in Amsterdam. Between the fourth and seventh day following delivery, the YHC centres record the date of delivery, infant sex, birth weight and gestational age (based on ultrasound or on the timing of the last menstrual period). During the first 14 months of life, the YHC centres conduct on average eight standardised routine measurements to monitor weight and length of infants. Because data collection from the YHC centres is still ongoing, data available up to 10 April 2009 were included in the analyses for the present study ( $n$ 2739).

The present study included only women with a pregnancy duration of 37 weeks or more who gave birth to live-born singletons without major congenital disorders and with data on all relevant study variables. This resulted in a subgroup of 3730 women when looking at birth weight and SGA. When examining weight and length, the numbers were 2365 and 2355, respectively (Fig. 1). The study was approved by the Central Committee on Research involving Human Subjects in The Netherlands, the Medical Ethical Committee of the participating hospitals and the Registration Committee of the Municipality of Amsterdam. Participants gave written informed consent.

\section{Outcome variables}

Outcome variables were birth weight, SGA and neonatal weight and length trajectories of neonates born at term (gestational age $\geq 37.0$ weeks). An infant was considered SGA when his or her birth weight fell below the tenth percentile of the most recent Dutch reference values (year 2008) for that gestational age according to parity and sex ${ }^{(29)}$. Neonatal weight and length trajectories were calculated by transforming each measurement as derived from the YHC records into sexand age-specific standard deviation scores (SDS) based on the total research population. Weight and length were examined at ages $1,3,6,9$ and 12 months.

\section{Independent variables}

For each participant of the biomarker study, a blood sample was taken in a $9 \mathrm{ml}$ evacuated tube (Vacuette; Breiner BV, Alphen aan de Rijn, The Netherlands), and it was sent to the Regional Laboratory of Amsterdam for processing (either by courier or by overnight mail in special envelopes). At the laboratory, serum was prepared by centrifugation ( $1600 \mathrm{~g}$ for $10 \mathrm{~min}$ at room temperature), and stored as $1 \mathrm{ml}$ aliquots at $-80^{\circ} \mathrm{C}$ until analysis. Serum 25-hydroxyvitamin D $(25(\mathrm{OH}) \mathrm{D})$ level was measured for 4250 women using an enzyme immunoassay method (OCTEIA AC-57F1 IDS Ltd, Boldon, UK). The intra- and inter-assay $\mathrm{CV}$ were $<8$ and $<10 \%$, respectively. Vitamin D measurements outside the detection range $(6-544 \mathrm{nmol} / \mathrm{l})$ were excluded from the analyses (n 14). Reliability was checked using the HIL index: serum specimens may contain $\mathrm{Hb}(\mathrm{H}$, haemolysis), bilirubin (I, icterus) and lipids (L, lipaemia) that can adversely impact clinical chemistry tests. When these interferents had values of $\mathrm{H}>1400$, I $>30$ and/or $\mathrm{L}>250$, the data were considered unreliable. Since there were no unreliable records, the seventy-one vitamin D measures that had a missing HIL index were considered reliable as well, and they were included for the analysis.

The pregnant woman's country of birth was used to determine ethnicity, except when she was Dutch and her mother was not; in such cases, the ethnicity of the mother 


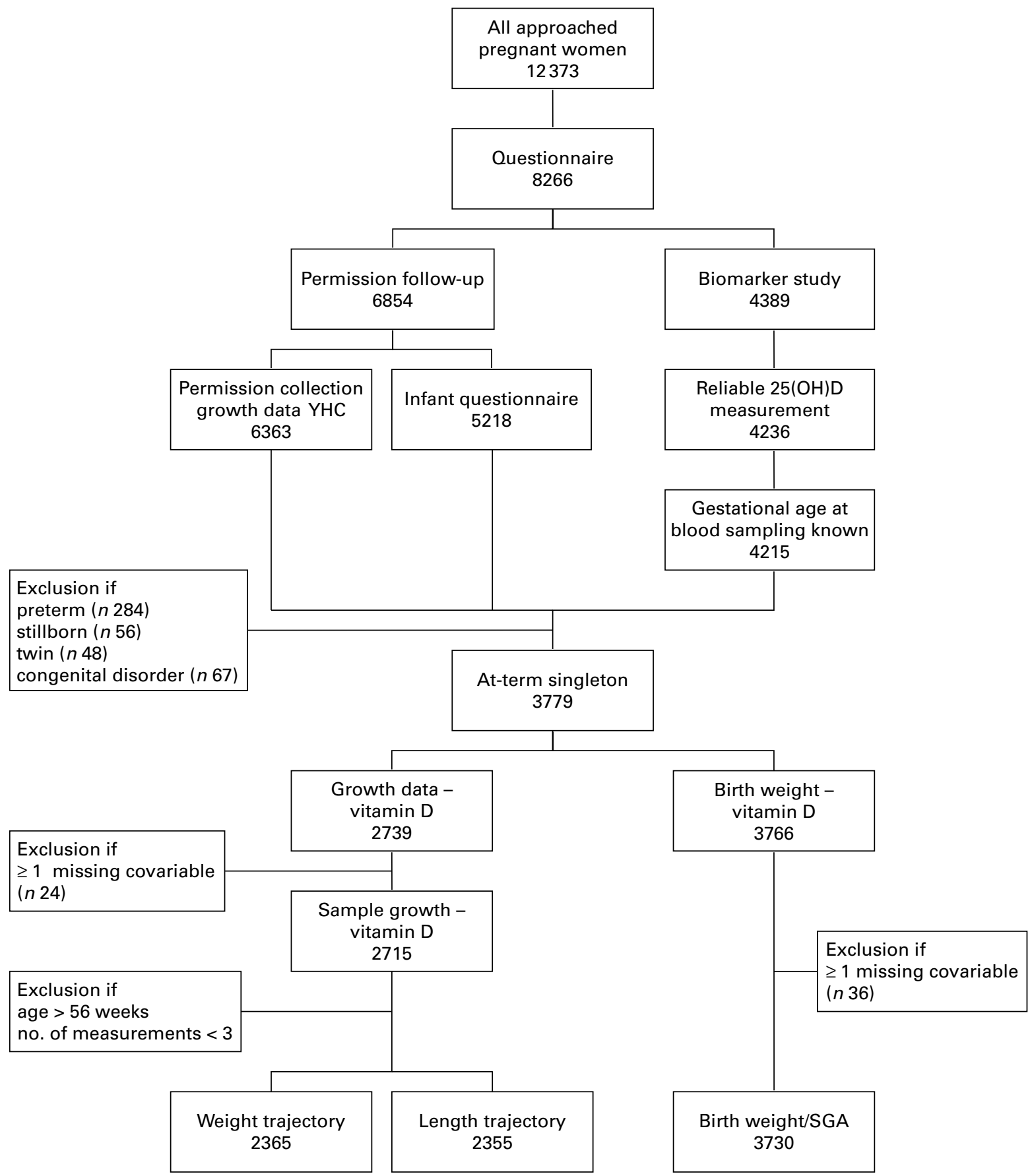

Fig. 1. Number of women included for the analyses of birth weight, SGA and infant weight and length after exclusion on predetermined criteria. YHC, youth health care; 25(OH)D, 25-hydroxyvitamin D; SGA, small-for-gestational-age.

was used. The following categories were distinguished: Dutch, Surinamese, Turkish, Moroccan, other non-Western and other Western. Within the ethnic minority groups, no distinction was made between first- and second-generation women as vitamin D exposure is not expected to differ between generations.

\section{Potential confounders}

The included covariates were physiological, lifestyle and socio-demographic characteristics of the pregnant women as obtained from the maternal questionnaire, and infant characteristics as derived from the infant questionnaire and the YHC records. The following relevant potential confounders were included ${ }^{(30,31)}$ : fetal sex, maternal height $(\mathrm{cm})$, parity $(0, \geq 1)$, maternal age $(\leq 24,25-34$ and $\geq 35$ years $)$, smoking (yes, no), maternal pre-pregnancy BMI (underweight: BMI $<18.5 \mathrm{~kg} / \mathrm{m}^{2}$, normal weight: $18 \cdot 5-24.9$, overweight: 25-29.9 and obese: $\geq 30$ ) and educational level (years of education after primary school: $\leq 5,6-10$ and $\geq 11$ years). When analysing neonatal growth, duration of exclusive breastfeeding $(0,1-3,4-6,>6$ months and unknown) was also included in the analyses. 


\section{Statistics}

It was decided a priori to categorise the vitamin D levels, because the relationship between a specific micronutrient and a health outcome is generally non-linear ${ }^{(32)}$. The categories were based on the Dutch literature ${ }^{(14,33,34)}$, and were distinguished as follows: $\leq 29.9 \mathrm{nmol} / 1$ ('deficient'), $30-49.9 \mathrm{nmol} / \mathrm{l}$ ('insufficient') and $\geq 50 \mathrm{nmol} / \mathrm{l}$ ('adequate'). Here, it should be noted that although we labelled $50 \mathrm{nmol} / \mathrm{l}$ as adequate, it is suggested that serum concentrations need to be as high as $80 \mathrm{nmol} / \mathrm{l}$ before an adequate level is reached ${ }^{(30)}$. However, consensus on this subject has not been reached $^{(30)}$.

Descriptive statistics were used to assess the percentage of women in each vitamin D category (deficient, insufficient or adequate), mean gestational age, mean birth weight, number of SGA infants and mean weight at months 1, 3, 6, 9 and 12 for the total cohort and for each vitamin D category separately. Differences in the distribution of characteristics between vitamin D categories were tested with either the $\chi^{2}$ test for categorical variables or ANOVA for continuous variables.

A linear regression analysis was performed to determine an association between vitamin D status and birth weight. A logistic regression analysis was performed to determine an association between vitamin D status and occurrence of SGA. Growth (weight and length SDS) was analysed using the general mixed model option in SPSS version 15.0 (SPSS Inc., Chicago, IL, USA). This statistical method is able to fit a model using longitudinal data, irrespective of differences in the number of repeated measurements or differences in intervals for different cases. To compare growth between the three vitamin $\mathrm{D}$ categories and between the six ethnic groups, a post hoc comparison (Fisher's least significant difference) was made at ages 4, 13, 26, 39 and 52 weeks (i.e. 1, 3, 6, 9 and 12 months).

In all the analyses, birth weight was standardised for gestational age, and vitamin D was standardised for the season when the blood samples were taken, since lower levels of vitamin D are measured during winter (November-April) and higher levels are measured during summer (May-October).

Five models were created for each outcome variable. Models 1 and 2 were the crude models for each independent variable separately (vitamin D status and ethnicity). Models 3 and 4 were the models adjusted for all the relevant potential confounders, again for each independent variable separately. Lastly, model 5 combined the adjusted models to include both vitamin $\mathrm{D}$ status and ethnicity. Vitamin $\mathrm{D}$ status $\times$ ethnicity interactions were tested by including the interaction term as a covariate to the fully adjusted model.

All data were analysed using SPSS version 15.0. Associations were considered significant at $P<0.05$, with the exception of the associations for weight SDS and length SDS: to reduce type I error with the multiple time measurements and post hoc analyses, these were considered statistically significant at $P<0 \cdot 01$.

\section{Results}

\section{Study subject characteristics}

In Table 1, maternal and infant characteristics are given for the total research population and for each vitamin D category separately. The median $25(\mathrm{OH}) \mathrm{D}$ concentration was 54.4 (interquartile range: $32-76) \mathrm{nmol} / \mathrm{l}$. Women with a deficient vitamin $\mathrm{D}$ status were on average younger and smaller, were not as likely to be expecting their first child, had a higher pre-pregnancy BMI and had a lower educational level compared with women with an insufficient or adequate vitamin $\mathrm{D}$ status. The mean birth weight for the entire group was 3515.6 (SD 489.1) $\mathrm{g}$ at a mean gestational age of $40 \cdot 1$ (SD 1.2) weeks. Of all of the infants, $9.2 \%$ were born SGA.

\section{Birth weight and small-for-gestational-age risk}

The crude analyses showed a significant association between a deficient vitamin D status and birth weight $(-114.4 \mathrm{~g}, 95 \%$ CI $-151 \cdot 2,-77 \cdot 6)$. An insufficient vitamin D status was also related to a lower birth weight, but not significantly (-35.5 g, 95\% CI - 73.0, 1.9; Table 2). Correspondingly, an increase of $140 \%$ in the risk of being SGA was observed in the deficient vitamin D category and an increase of $50 \%$ in this risk was observed in the insufficient category, both compared with the adequate category $(\geq 50 \mathrm{nmol} / \mathrm{l})$. After adjustment for all the potential confounders (Adjusted 2), the associations with birth weight and SGA risk remained significant for the deficient vitamin D category (birth weight $-64.0 \mathrm{~g}, 95 \%$ CI $-107 \cdot 1,-20.9$; SGA $1.9,95 \%$ CI $1.4,2 \cdot 7)$.

Table 2 also shows that a minor part of the differences in birth weight (approximately $25 \mathrm{~g}$ ) between the Dutch and ethnic minority groups can be attributed to differences in vitamin D status. After full adjustment (model 5), birth weight remained significantly lower for the Surinamese group and significantly higher for the Turkish group. The estimated SGA risk decreased to $1.5(95 \%$ CI $1.0,2.3)$ in the Surinamese group and to $0.4(95 \%$ CI $0.2,0.8)$ in the Turkish group. Vitamin D status $\times$ ethnicity interaction was not detected for either birth weight or SGA $(P>0.05)$.

\section{Neonatal weight and length}

Table 3 (weight) and Table 4 (length) show the crude (model 1) and adjusted (model 3) SDS at ages 1, 3, 6, 9 and 12 months for each vitamin $\mathrm{D}$ group. The growth patterns as determined by the fully adjusted model (model 5) are presented in Fig. 2(a) (weight) and Fig. 2(b) (length). Overall, no differences were observed between the adequate and insufficient vitamin D groups. However, in Table 3, the weight model adjusted for the potential confounders, but not for ethnic group, shows that compared with infants born to mothers with an adequate vitamin D status, infants born to mothers in the deficient category had significantly higher weights at months 6 and 9 . Analyses of length showed that infants in the deficient category were significantly smaller at month 1 , but significantly larger at 12 months of age.

From Fig. 2(a) and (b), it can be observed that additional adjustment for ethnic group did not change the pattern of the growth trajectories of weight and length. Compared with the adequate group, both weight and length of the deficient group were significantly lower until month 3 , with the difference completely disappearing between weeks 13 and 26. After week 26, however, length continued to increase, reaching 
Table 1. Maternal and infant characteristics and neonatal outcomes for the total population and per vitamin $D$ category (Mean values and standard deviations)

\begin{tabular}{|c|c|c|c|c|c|c|c|c|c|}
\hline & \multicolumn{2}{|c|}{ All $(n 3730)$} & \multicolumn{2}{|c|}{$\begin{array}{c}\text { Deficient } \\
\text { vitamin D status } \\
(\leq 29.9 \mathrm{nmol} / \mathrm{l} \\
n 861)\end{array}$} & \multicolumn{2}{|c|}{$\begin{array}{c}\text { Insufficient } \\
\text { vitamin D status } \\
(30-49.9 \mathrm{nmol} / \mathrm{l} \\
n 797)\end{array}$} & \multicolumn{2}{|c|}{$\begin{array}{c}\text { Adequate } \\
\text { vitamin D status } \\
(\geq 50 \mathrm{nmol} / \mathrm{l} \\
n 2072) \dagger\end{array}$} & \multirow[b]{2}{*}{$P \ddagger$} \\
\hline & Mean & SD & Mean & SD & Mean & SD & Mean & SD & \\
\hline \multicolumn{10}{|l|}{ 25(OH)D (nmol/l) } \\
\hline Median & \multirow{2}{*}{\multicolumn{2}{|c|}{54.4}} & \multicolumn{2}{|c|}{$19 \cdot 9$} & \multicolumn{2}{|c|}{$40 \cdot 4$} & \multicolumn{2}{|c|}{$73 \cdot 3$} & \\
\hline Interquartile range & & & \multirow{2}{*}{\multicolumn{2}{|c|}{$\begin{array}{r}15-25 \\
25 \cdot 9^{*}\end{array}$}} & \multicolumn{2}{|c|}{$35-45$} & \multirow{2}{*}{\multicolumn{2}{|c|}{$\begin{array}{c}62-90 \\
56 \cdot 1\end{array}$}} & \\
\hline Season of $25(\mathrm{OH}) \mathrm{D}$ measurement (\% summer) & \multicolumn{2}{|c|}{43.6} & & & & & & & $<0.001$ \\
\hline Gestational age at blood sampling (weeks) & 13.5 & $3 \cdot 3$ & $14 \cdot 6^{\star}$ & $4 \cdot 0$ & $13 \cdot 6^{\star}$ & $3 \cdot 2$ & $13 \cdot 1$ & 2.9 & $<0.001$ \\
\hline \multicolumn{10}{|l|}{ Maternal characteristics } \\
\hline Ethnic group (\%) & & & & & & & & & $<0.001$ \\
\hline Dutch ( $n$ 2248) & \multicolumn{2}{|c|}{$60 \cdot 3$} & \multicolumn{2}{|c|}{$21 \cdot 3^{*}$} & & & & & \\
\hline Surinamese (n 249) & & & & & & & & & \\
\hline Turkish ( $n$ 149) & & & & & & & & & \\
\hline Moroccan (n 234) & & & & & & & & & \\
\hline Other non-Western ( $n$ 529) & & & & & & & & & \\
\hline Other Western ( $n$ 321) & & & & & & & & & \\
\hline Maternal height $(\mathrm{cm})$ & $169 \cdot 1$ & $7 \cdot 1$ & $165 \cdot 5^{*}$ & $7 \cdot 1$ & $168 \cdot 3^{*}$ & $7 \cdot 2$ & $170 \cdot 9$ & $6 \cdot 4$ & $<0.001$ \\
\hline Nulliparity (\%) & & & & & & & & & $<0.001$ \\
\hline Maternal age (\%) & & & & & & & & & $<0.001$ \\
\hline$\leq 24$ years & & & & & & & & & \\
\hline $25-34$ years & & & & & & & & & \\
\hline$\geq 35$ years & & & & & & & & & \\
\hline Smoking during pregnancy (\% yes) & & & & & & & & & $<0.001$ \\
\hline Maternal pre-pregnancy BMI (\%) & & & & & & & & & $<0.001$ \\
\hline Underweight & & & & & & & & & \\
\hline Normal weight & & & & & & & & & \\
\hline Overweight & & & & & & & & & \\
\hline Obese & & & & & & & & & \\
\hline Education (\%) & & & & & & & & & $<0.001$ \\
\hline$\leq 5$ years & & & & & & & & & \\
\hline $6-10$ years & & & & & & & & & \\
\hline$\geq 11$ years & & & & & & & & & \\
\hline Exclusive breastfeeding first year (\%) & & & & & & & & & 0.017 \\
\hline None & & & & & & & & & \\
\hline $1-3$ months & & & & & & & & & \\
\hline $4-6$ months & & & & & & & & & \\
\hline$>6$ months & & & & & & & & & \\
\hline Unknown & & & & & & & & & \\
\hline Infant characteristics & & & & & & & & & \\
\hline Infant sex (\% boy) & & & & & & & & & 0.292 \\
\hline Gestational age at birth (weeks) & $40 \cdot 1$ & 1.2 & $40 \cdot 0^{\star}$ & $1 \cdot 2$ & $40 \cdot 0^{\star \star}$ & $1 \cdot 2$ & $40 \cdot 2$ & $1 \cdot 2$ & $<0.001$ \\
\hline Birth weight $(\mathrm{g})$ & $3515 \cdot 6$ & $489 \cdot 1$ & $3418 \cdot 4^{*}$ & $510 \cdot 3$ & $3505 \cdot 6^{\star \star}$ & $496 \cdot 2$ & 3559.8 & $471 \cdot 3$ & $<0.001$ \\
\hline SGA at birth (\%) & & & & & & & & & $<0.001$ \\
\hline Infant weight (g) at age & & & & & & & & & \\
\hline 1 month & $4409 \cdot 4$ & $12 \cdot 2$ & $4348 \cdot 4^{\star *}$ & $24 \cdot 8$ & $4405 \cdot 5$ & $26 \cdot 3$ & 4437.3 & $16 \cdot 4$ & 0.012 \\
\hline 3 months & $6010 \cdot 8$ & $13 \cdot 9$ & $6021 \cdot 1$ & $28 \cdot 3$ & $5995 \cdot 2$ & $30 \cdot 0$ & $6012 \cdot 4$ & $18 \cdot 8$ & 0.814 \\
\hline 6 months & $7832 \cdot 9$ & $18 \cdot 0$ & $7911 \cdot 7^{\star \star \star}$ & $36 \cdot 7$ & $7805 \cdot 5$ & 38.9 & $7809 \cdot 2$ & $24 \cdot 3$ & 0.049 \\
\hline 9 months & $9074 \cdot 6$ & $20 \cdot 3$ & $9181 \cdot 3^{\star \star}$ & 41.5 & 9041.9 & $43 \cdot 9$ & 9040.7 & $27 \cdot 4$ & 0.013 \\
\hline 12 months & 9735.9 & $22 \cdot 6$ & $9829 \cdot 8^{* * *}$ & $46 \cdot 2$ & $9704 \cdot 2$ & $48 \cdot 8$ & $9706 \cdot 8$ & $30 \cdot 5$ & 0.065 \\
\hline Infant length $(\mathrm{cm})$ at age & & & & & & & & & \\
\hline 1 month & $54 \cdot 8$ & 0.05 & $54 \cdot 2^{*}$ & 0.09 & $54 \cdot 8^{\star * \star}$ & $0 \cdot 10$ & $55 \cdot 1$ & 0.06 & $<0.001$ \\
\hline 3 months & $60 \cdot 8$ & 0.04 & $60 \cdot 4^{*}$ & 0.09 & $60 \cdot 8$ & 0.09 & $61 \cdot 0$ & 0.06 & $<0.001$ \\
\hline 6 months & $67 \cdot 6$ & 0.05 & $67 \cdot 4^{\star \star}$ & $0 \cdot 10$ & $67 \cdot 6$ & $0 \cdot 10$ & $67 \cdot 7$ & 0.06 & 0.028 \\
\hline 9 months & $72 \cdot 4$ & 0.05 & $72 \cdot 3$ & 0.10 & $72 \cdot 3$ & 0.10 & $72 \cdot 4$ & 0.07 & 0.665 \\
\hline 12 months & $75 \cdot 0$ & 0.06 & $75 \cdot 1$ & 0.12 & $75 \cdot 0$ & 0.12 & $75 \cdot 0$ & 0.08 & 0.634 \\
\hline
\end{tabular}

25(OH)D, 25-hydroxyvitamin D; SGA, small for gestational age.

Mean values were significantly different from reference: * $P<0.001 ;{ }^{\star *} P<0.01 ;{ }^{\star \star \star} P<0.05$

†Reference group.

$\ddagger P$ for differences between vitamin $D$ groups tested with $\chi^{2}$ for categorical variables or ANOVA for continuous variables.

significance at months 9 and 12 . Weight also increased after week 26, but converged to the adequate category in week 52 .

Fig. 3(a) and (b) show the growth patterns for each ethnic group as determined by the fully adjusted model (model 5). None of the differences in weight and length between the
Dutch and ethnic minority groups were explained by vitamin D status (model 4 and model 5 are similar, data not shown). From Fig. 3(a), it can be observed that the Turkish infants were significantly heavier than the Dutch infants during the first year of life. The Moroccan infants were significantly 
Table 3. Mean weight standard deviation scores (SDS) for the vitamin $D$ categories at ages 1, 3, 6, 9 and 12 months

(Mean values with their standard errors)

\begin{tabular}{|c|c|c|c|c|c|}
\hline & \multirow[b]{3}{*}{$\begin{array}{c}\text { Age } \\
\text { (months) }\end{array}$} & \multicolumn{4}{|c|}{ Weight } \\
\hline & & \multicolumn{2}{|c|}{ Crude SDS } & \multicolumn{2}{|c|}{ Adjusted SDS* } \\
\hline & & Mean & SE & Mean & SE \\
\hline \multicolumn{6}{|l|}{ Vitamin D group $†$} \\
\hline \multicolumn{6}{|l|}{ Deficient } \\
\hline & 1 & $-0.12 \ddagger$ & 0.04 & -0.02 & 0.05 \\
\hline & 3 & $<0.01$ & 0.04 & 0.09 & 0.05 \\
\hline & 6 & 0.10 & 0.04 & $0.19 \ddagger$ & 0.05 \\
\hline & 9 & 0.12 & 0.04 & $0.21 \ddagger$ & 0.06 \\
\hline & 12 & 0.07 & 0.04 & 0.16 & 0.06 \\
\hline \multicolumn{6}{|l|}{ Insufficient } \\
\hline \multirow[t]{5}{*}{$(30-49.9 \mathrm{nmol} / \mathrm{l})$} & 1 & 0.07 & 0.05 & 0.11 & 0.06 \\
\hline & 3 & 0.03 & 0.04 & 0.08 & 0.05 \\
\hline & 6 & $<0.01$ & 0.05 & 0.05 & 0.06 \\
\hline & 9 & $<0.01$ & 0.05 & 0.05 & 0.06 \\
\hline & 12 & 0.03 & 0.05 & 0.07 & 0.06 \\
\hline \multirow{6}{*}{$\begin{array}{l}\text { Adequate } \\
\qquad(\geq 50 \mathrm{nmol} / \mathrm{l}) \S\end{array}$} & & & & & \\
\hline & 1 & 0.13 & 0.03 & 0.11 & 0.05 \\
\hline & 3 & 0.06 & 0.03 & 0.05 & 0.05 \\
\hline & 6 & 0.01 & 0.03 & -0.01 & 0.05 \\
\hline & 9 & $<0.001$ & 0.03 & -0.02 & 0.05 \\
\hline & 12 & 0.04 & 0.03 & 0.02 & 0.05 \\
\hline
\end{tabular}

${ }^{*}$ Adjusted for gestational age, season of vitamin D measurement, infant sex maternal height, parity, maternal age, smoking, pre-pregnancy BMI, educational level and duration of exclusive breastfeeding.

† Standardised for season of vitamin D measurement.

$\ddagger$ Mean values were significantly different from reference $(P<0.01)$.

$\S$ Reference group.

heavier at months 6,9 and 12 . The Surinamese infants were relatively light, but did not differ significantly from the Dutch infants. However, they were significantly smaller at months 1 and 3 (Fig. 3(b)). The Turkish infants were larger at months 6,9 and 12 , and the differences between the Dutch and Moroccan infants did not reach significance. No vitamin $\mathrm{D}$ status $\times$ ethnicity interaction was detected for either weight or length $(P>0.05)$.

\section{Discussion}

To our knowledge, this is the first large-scale study to prospectively investigate the relationship between maternal vitamin D status and offspring outcomes in a multi-ethnic cohort. It shows that infants born to mothers with early pregnancy vitamin D levels $\leq 29.9 \mathrm{nmol} / 1$ had significantly lower birth weights and an increased risk of SGA compared with infants born to mothers with levels $\geq 50 \mathrm{nmol} / 1$.

Previous reports have shown inconsistent results for associations between maternal $25(\mathrm{OH}) \mathrm{D}$ concentrations and measures of birth size ${ }^{(10,35-37)}$. Brooke et al. ${ }^{(10)}$ randomly supplemented Asian women with vitamin D during their third trimester of pregnancy. They ${ }^{(10)}$ found that birth weights of children born at term did not differ between mothers in the vitamin D-supplemented group and mothers in the non-supplemented group, although the supplementation did raise the women's $25(\mathrm{OH}) \mathrm{D}$ concentrations. However, they did report that the percentage of SGA-born infants was twice as high in the non-supplemented group compared with the 
Table 4. Mean length standard deviation scores (SDS) for the vitamin $D$ categories at ages 1, 3, 6, 9 and 12 months

(Mean values with their standard errors)

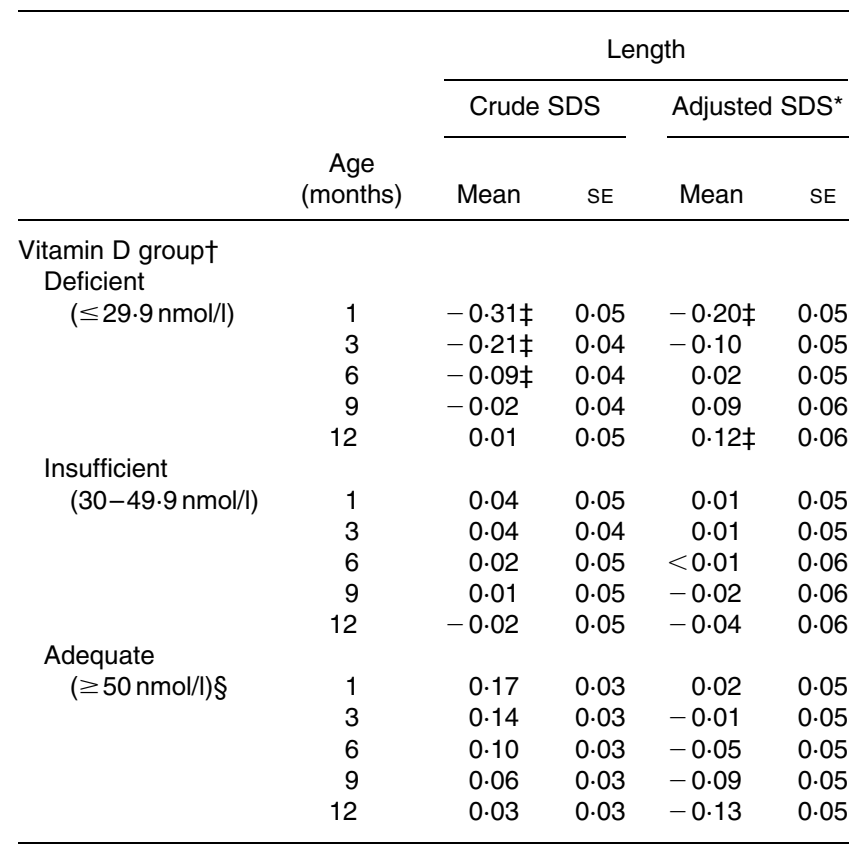

*Adjusted for gestational age, season of vitamin D measurement, infant sex, maternal height, parity, maternal age, smoking, pre-pregnancy BMI, educational level and duration of exclusive breastfeeding.

† Standardised for season of vitamin D measurement.

$\ddagger$ Mean values were significantly different from reference $(P<0.01)$.

$\S$ Reference group.

supplemented group. The latter result is consistent with Marya et al. ${ }^{(35)}$ who also found a lower prevalence of low birth weight infants in the supplemented group. However, both the studies by Brooke et al. ${ }^{(10)}$ and Marya et al. ${ }^{(35)}$ were conducted among Asian women at high risk of vitamin D deficiency, and comparison to the present results should therefore be made with caution. An observational study by Morley et al. ${ }^{(36)}$ found no association between $25(\mathrm{OH}) \mathrm{D}$ concentration and birth weight. They ${ }^{(36)}$ measured maternal 25(OH)D concentrations about the twenty-eighth week of gestation; this was the thirteenth week of gestation in the present study. At present, it is not known whether maternal vitamin D levels track over gestation, since results obtained from the investigation of vitamin $\mathrm{D}$ in gestation are inconclusive ${ }^{(38,39)}$. We therefore do not know which stage in pregnancy is most relevant, but it is possible that an association between $25(\mathrm{OH}) \mathrm{D}$ concentration and measures of birth size is prevalent when measuring $25(\mathrm{OH}) \mathrm{D}$ concentration early in pregnancy, at which stage the growth trajectory is set ${ }^{(3,4)}$ and bone development starts ${ }^{(5,6)}$. Although this explains the present results in comparison with afore-mentioned studies ${ }^{(10,35,36)}$, longitudinal studies with repeated measurements during pregnancy would be required to confirm these associations.

In the present study, infants of mothers with a deficient vitamin D status showed accelerated growth in weight and length. This increased growth velocity might be explained by the Dutch policy to advice parents to supplement their child with vitamin D droplets when exclusively breastfed. When not exclusively breastfed, infants receive vitamin D from fortified bottle-feedings. Thus, after birth, infants depend no longer on the vitamin D status of their mother, and consequently, may increase their growth velocity.

Accelerated growth may have important long-term implications, since it is associated with increased risk of obesity $^{(40-42)}$. Interestingly, not only accelerated infant growth, but also poor infant growth in combination with accelerated weight gain during childhood is associated with increased risk of CHD and insulin resistance ${ }^{(43-45)}$. To our knowledge, only one previous small study by Brooke et al. ${ }^{(11)}$ explored vitamin D levels in relation to postnatal growth. They reported significantly higher weights at 3, 6, 9 and 12 months in children whose Asian mothers, at high risk of vitamin D deficiency, received vitamin D supplementation during the last trimester. Infant length only differed significantly at months 9 and 12 . These data are best compared with the weight and length measures given in Table 1, where a different observation is made. Our results showed that compared with the adequate group, mean infant weight of a child born to a mother with a deficient vitamin D status was significantly lower at month 1 and significantly higher at months 6, 9 and 12. In contrast to the results reported by Brooke et al. ${ }^{(11)}$, mean length was significantly lower at months 1,3 and 6 , and it did not differ from that of the adequate group at months 9 and 12 . The insufficient group showed only a significant lower mean length at month 1 and no differences in mean weight. These inconsistencies may be due to the large difference in $25(\mathrm{OH}) \mathrm{D}$ concentration between the non-supplemented and supplemented group $(16 \cdot 2$ v. $168 \cdot 0 \mathrm{nmol} / \mathrm{l})$ that Brooke et al. ${ }^{(11)}$ reported compared
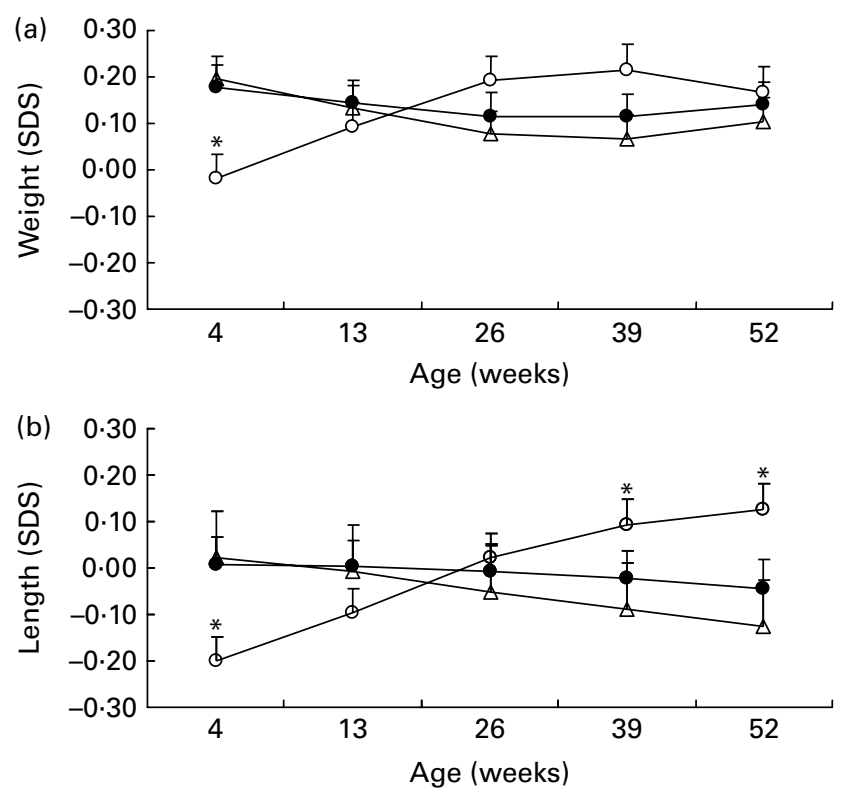

Fig. 2. Estimated standard deviation scores (SDS) of infant weight (a) and infant length (b) as a function of age. Adjusted for gestational age, season of vitamin D collection, infant sex, maternal height, parity, maternal age, smoking, pre-pregnancy BMI, educational level, duration of exclusive breastfeeding and ethnic group. Results are shown for each maternal vitamin D category ('deficient' $(\leq 29.9 \mathrm{nmol} / \mathrm{l})$, 'insufficient' $(30-49.9 \mathrm{nmol} / \mathrm{l})$ and 'adequate' ( $\geq 50 \mathrm{nmol} / \mathrm{l})$. Standard error of the mean is represented by vertical bars. * Mean values were significantly different from the adequate category $(P<0.01)$. Estimates for SDS were derived from a multivariate mixed model analysis. $-\bigcirc-$, Deficient; $-\bullet-$, insufficient; $-\triangle-$, adequate. 

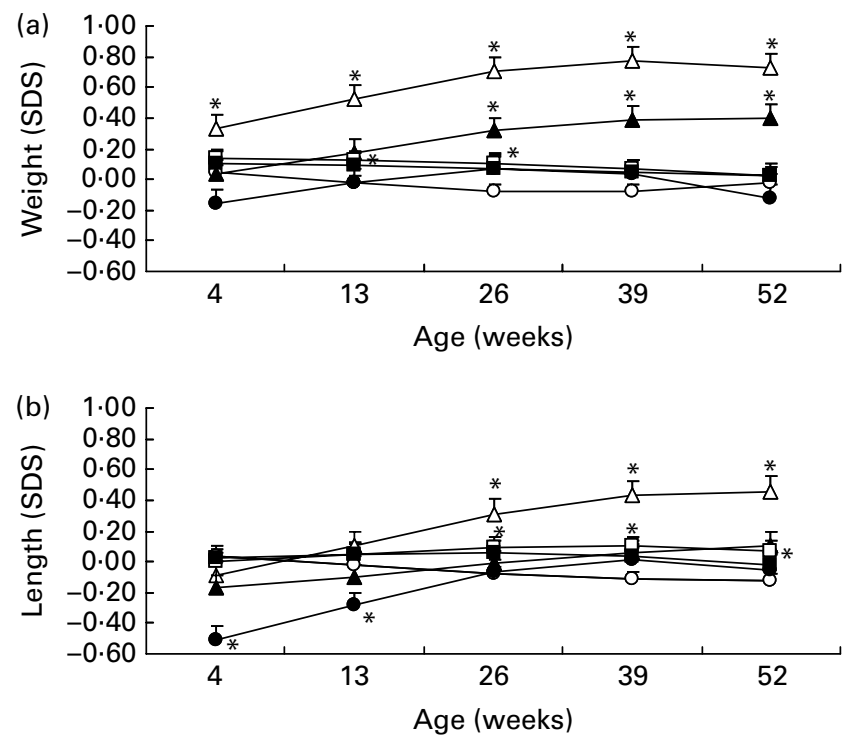

Fig. 3. Estimated standard deviation scores (SDS) of infant weight (a) and infant length (b) as a function of age. Adjusted for gestational age, infant sex, maternal height, parity, maternal age, smoking, pre-pregnancy BMI, educational level, duration of exclusive breastfeeding and vitamin D group. Results are shown for each ethnic group (Dutch, Surinamese, Turkish, Moroccan, other non-Western and other Western). Standard error of the mean is represented by vertical bars. * Mean values were significantly different from the Dutch $(P<0.01)$. Estimates for SDS were derived from a multivariate mixed model analysis. $-\bigcirc-$, Dutch; -๑-, Surinamese; $-\triangle-$, Turkish;

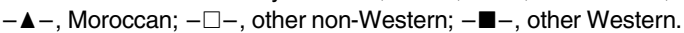

with the relatively small differences in concentration between the three vitamin D categories in the present study. Future research should aim at designing studies to further investigate associations between vitamin D and infant growth measures as well as to examine growth beyond 12 months of age in order to assess the relationship with health outcomes later in life.

The present study confirms the high prevalence of vitamin $\mathrm{D}$ deficiency among ethnic minorities in northern countries $^{(12-14)}$ as well as the lower birth weights of their infants when compared with indigenous newborns ${ }^{(20-22)}$. The disparities between the Dutch native and ethnic minority populations in vitamin $\mathrm{D}$ status might be explained by differences in skin pigmentation ${ }^{(15-17)}$. Other factors to be considered are differences in nutritional habits ${ }^{(9,10)}$ and amount of sun exposure ${ }^{(18,19)}$. For example, in a study by Grover \& Morley $^{(19)}, 80 \%$ of dark-skinned and/or veiled women were at high risk of vitamin D levels below $22.5 \mathrm{nmol} / 1$.

In Surinamese people, the relatively heavy pigment is thought to play a large role, whereas Turkish and Moroccan people have a traditional clothing style that prevents their skin from being exposed to the sun. Although only a small portion of vitamin D generally comes from food, it may be a relatively important factor for the ethnic minority groups, because when dermal synthesis is low, dietary adequacy becomes important. When food intake of vitamin $\mathrm{D}$ is also low (which may be more common among those from ethnic minorities than among the Dutch), it may aggravate an already low vitamin D level. These low levels are of no concern if vitamin $\mathrm{D}$ is used more efficiently. However, as we found no significant interaction between vitamin $\mathrm{D}$ status and ethnicity, there do not seem to be any ethnic differences in metabolic efficiency of vitamin D between ethnic groups.
Vitamin D status appears to play a limited role in explaining some of the existing differences in birth weight between ethnic groups. In the Moroccan, other non-Western and other Western groups, vitamin D status did not provide an additional contribution on top of adjustment for all the potential confounders. In the Surinamese and Turkish groups, however, vitamin D status explained approximately $25 \mathrm{~g}$ of the difference with the Dutch infants. The differences in infant weight and length trajectories between ethnic groups were not explained by maternal vitamin D status. However, it should be taken into account that the present study only investigated vitamin $\mathrm{D}$, while it is very likely that the maternal food and behavioural pattern as a whole influence neonatal health outcomes. Therefore, although the contribution of vitamin D found in the present study was relatively small, it might be an important factor in relation to other nutrients, such as $\mathrm{Ca}$.

Some strengths and limitations of the present study should also be discussed. The present study is part of a large population-based longitudinal study that uses questionnaires in different languages to include all ethnic minority groups. However, analyses were performed only on the data of women whose vitamin $\mathrm{D}$ status had been measured and where growth data of their children were available. Because this resulted in a relatively healthy sample of pregnant women, the results may be too conservative. Strengths also include the use of a reliable set of growth data obtained from care providers and detailed information on a range of covariables. Nonetheless, some residual confounding resulting from missing data on breastfeeding (no known end date for $26.7 \%$ of women) might be present. However, when breastfeeding was categorised as $0,1-3$ or $>3$ months (which allowed for better classification of women because of available information on the 3-month questionnaire), it had no effect on the growth model. To eliminate confounding by preterm and multiple births, only singleton term-born infants were included. An adjustment was made for season of vitamin D collection but not for gestational age at blood sampling, because season is considered to be more important ${ }^{(38,46,47)}$, and the literature on the relationship between gestational age and vitamin D levels, as noted before, is inconsistent ${ }^{(38,39)}$.

In conclusion, the results of the present study show that a deficient maternal vitamin D status is associated with lower birth weight, higher SGA risk and altered neonatal growth, both in weight and in length, but in itself makes a limited contribution to explaining ethnic differences in these outcomes. Nonetheless, vitamin D plays an important role in a range of health-related processes, and the poor vitamin D status in several ethnic minority groups indicates the beneficial role of extra vitamin D on an individual level, not only to improve a woman's health, but possibly also to improve that of her child, both before and after birth. The Health Council of The Netherlands recognises the importance of vitamin D, as shown by their renewed recommendation on vitamin D supplementation to achieve the minimum required level of vitamin D status ${ }^{(34)}$. Although the Health Council recommends a higher intake for pregnant women than for nonpregnant women, this advice has still not been fully integrated in practice (e.g. health services). The present study indicates that although vitamin D supplementation might be beneficial for certain groups, more research is needed before a nationwide policy on the subject can be justified. 


\section{Acknowledgements}

E. R. L. and M. v. E. developed the concept of the present study as part of the ABCD study. E. R. L. conducted the analyses. M. V. E. and T. G. M. V. provided statistical advice. M. v. E. and T. G. M. V. are project managers of the ABCD study, and they co-ordinated the data collection. E. R. L. was involved in obtaining part of the data. All the authors contributed to interpreting the results and writing the article, and they have seen and approved the final version. None of the authors have a personal or financial conflict of interest. The ABCD study was financially supported by a research grant from The Netherlands Organisation for Health Research and Development (grant number 21000076). The National Institute for Public Health and the Environment co-financed the vitamin D analyses. We are grateful to all participating hospitals, obstetric clinics and general practitioners for their assistance in implementing the ABCD study, and we thank all the women who participated for their cooperation.

\section{References}

1. Barker DJ (2004) The developmental origins of adult disease. $J$ Am Coll Nutr 23, Suppl. 6, 588S-595S.

2. Hollis BW \& Wagner CL (2006) Nutritional vitamin D status during pregnancy: reasons for concern. CMAJ 174, 1287-1290.

3. Godfrey KM \& Barker DJ (2001) Fetal programming and adult health. Public Health Nutr 4, 611-624.

4. Smith GC (2004) First trimester origins of fetal growth impairment. Semin Perinat 28, 41-50.

5. Prefumo F, Canini S, Crovo A, et al. (2006) Correlation between first trimester fetal bone length and maternal serum pregnancy-associated plasma protein-A (PAPP-A). Hum Reprod 21, 3019-3021.

6. Mahon P, Harvey N, Crozier S, et al. (2009) Low maternal vitamin D status and fetal bone development: cohort study. J Bone Miner Res (Epublication ahead of print version 6 July 2009).

7. Cooper C, Javaid K, Westlake S, et al. (2005) Developmental origins of osteoporotic fracture: the role of maternal vitamin D insufficiency. J Nutr 135, 2728S-2734S.

8. Pawley N \& Bishop NJ (2004) Prenatal and infant predictors of bone health: the influence of vitamin D. Am J Clin Nutr $\mathbf{8 0}$, Suppl. 6, 1748S-1751S.

9. Scholl TO \& Chen X (2009) Vitamin D intake during pregnancy: association with maternal characteristics and infant birth weight. Early Hum Dev 85, 231-234.

10. Brooke OG, Brown IR, Bone CD, et al. (1980) Vitamin D supplements in pregnant Asian women: effects on calcium status and fetal growth. Br Med J 280, 751-754.

11. Brooke OG, Butters F \& Wood C (1981) Intrauterine vitamin D nutrition and postnatal growth in Asian infants. Br Med J (Clin Res Ed) 283, 1024.

12. Fuller KE (2000) Low birth-weight infants: the continuing ethnic disparity and the interaction of biology and environment. Ethn Dis 10, 432-445.

13. van der Meer I, Karamali NS, Boeke AJ, et al. (2006) High prevalence of vitamin D deficiency in pregnant non-Western women in The Hague, Netherlands. Am J Clin Nutr 84, 350-353.

14. Wielders JP, van Dormael PD, Eskes PF, et al. (2006) Severe vitamin-D deficiency in more than half of the immigrant pregnant women of non-western origin and their newborns (in Dutch). Ned Tijdschr Geneeskd 150, 495-499.
15. Clemens TL, Adams JS, Henderson SL, et al. (1982) Increased skin pigment reduces the capacity of skin to synthesise vitamin $\mathrm{D}_{3}$. Lancet 1, 74-76.

16. Holick MF (1995) Environmental factors that influence the cutaneous production of vitamin D. Am J Clin Nutr 61, Suppl. 3, 638S-645S.

17. Norman AW (1998) Sunlight, season, skin pigmentation, vitamin $\mathrm{D}$, and 25-hydroxyvitamin D: integral components of the vitamin $\mathrm{D}$ endocrine system. Am J Clin Nutr 67, $1108-1110$.

18. Gannage-Yared MH, Chemali R, Yaacoub N, et al. (2000) Hypovitaminosis D in a sunny country: relation to lifestyle and bone markers. J Bone Miner Res 15, 1856-1862.

19. Grover SR \& Morley R (2001) Vitamin D deficiency in veiled or dark-skinned pregnant women. Med J Aust 175, 251-252.

20. van der Wal MF, Uitenbroek DG \& van Buuren S (2000) Birth weight of children in Amsterdam by ethnic origin (in Dutch). Tijdschrift voor Gezondheidswetenschappen 78, 15-20.

21. Troe EJ, Raat H, Jaddoe VW, et al. (2007) Explaining differences in birthweight between ethnic populations. The Generation R Study. BJOG 114, 1557-1565.

22. Kelly Y, Panico L, Bartley M, et al. (2009) Why does birthweight vary among ethnic groups in the UK? Findings from the Millennium Cohort Study. J Public Health (Oxf) 31, $131-137$.

23. Tate AR, Dezateux C \& Cole TJ (2006) Is infant growth changing? Int J Obes (Lond) 30, 1094-1096.

24. Bansal N, Ayoola OO, Gemmell I, et al. (2008) Effects of early growth on blood pressure of infants of British European and South Asian origin at one year of age: the Manchester children's growth and vascular health study. J Hypertens 26, 412-418.

25. Bulk-Bunschoten AM, Pasker-de Jong PC, van Wouwe JP, et al. (2008) Ethnic variation in infant-feeding practices in the Netherlands and weight gain at 4 months. J Hum Lact 24, 42-49.

26. Zhang A, Sayre JW, Vachon L, et al. (2009) Racial differences in growth patterns of children assessed on the basis of bone age. Radiology 250, 228-235.

27. van Eijsden M, van der Wal MF \& Bonsel GJ (2006) Folic acid knowledge and use in a multi-ethnic pregnancy cohort: the role of language proficiency. BJOG 113, 1446-1451.

28. van Eijsden M, Hornstra G, van der Wal MF, et al. (2009) Ethnic differences in early pregnancy maternal $n-3$ and $n-6$ fatty acid concentrations: an explorative analysis. $\mathrm{Br} J \mathrm{Nutr}$ 101, 1761-1768.

29. Stichting Perinatale Registratie Nederland (PRN) (2008) The Netherlands Perinatal Registry Birth weight centiles and SD. http://www.perinatreg.nl/referentiecurven?noCache $=662 ; 12501$ 68307

30. Holick MF \& Chen TC (2008) Vitamin D deficiency: a worldwide problem with health consequences. Am J Clin Nutr 87, 1080S-1086S

31. Goedhart G, van Eijsden M, van der Wal MF, et al. (2008) Ethnic differences in term birthweight: the role of constitutional and environmental factors. Paediatr Perinat Epidemiol 22, 360-368.

32. Willett WC (1998) Nutritional Epidemiology, 2nd ed., pp. 323-324. New York: Oxford University Press.

33. Grootjans-Geerts I (2006) Vitamin D: important from before the cradle and to the grave (in Dutch). Ned Tijdschr Geneeskd 150, $470-472$.

34. Health Council of The Netherlands (2008) Towards an Adequate Intake of Vitamin D (in Dutch). Report no. 2008/15. The Hague: Health Council of The Netherlands.

35. Marya RK, Rathee S, Dua V, et al. (1988) Effect of vitamin D supplementation during pregnancy on foetal growth. Indian $J$ Med Res 88, 488-492. 
36. Morley R, Carlin JB, Pasco JA, et al. (2006) Maternal 25-hydroxyvitamin $\mathrm{D}$ and parathyroid hormone concentrations and offspring birth size. J Clin Endocrinol Metab 91, 906-912.

37. Mannion CA, Gray-Donald K \& Koski KG (2006) Association of low intake of milk and vitamin $\mathrm{D}$ during pregnancy with decreased birth weight. CMAJ 174, 1273-1277.

38. Ainy E, Ghazi AA \& Azizi F (2006) Changes in calcium, $25(\mathrm{OH})$ vitamin $\mathrm{D} 3$ and other biochemical factors during pregnancy. J Endocrinol Invest 29, 303-307.

39. Kovacs CS (2008) Vitamin D in pregnancy and lactation: maternal, fetal, and neonatal outcomes from human and animal studies. Am J Clin Nutr 88, Suppl. 2, 520S-528S.

40. Ong KK, Ahmed ML, Emmett PM, et al. (2000) Association between postnatal catch-up growth and obesity in childhood: prospective cohort study. BMJ 320, 967-971.

41. Stettler N, Zemel BS, Kumanyika S, et al. (2002) Infant weight gain and childhood overweight status in a multicenter, cohort study. Pediatrics 109, 194-199.
42. Stettler N, Kumanyika SK, Katz SH, et al. (2003) Rapid weight gain during infancy and obesity in young adulthood in a cohort of African Americans. Am J Clin Nutr 77, 1374-1378.

43. Hales CN, Barker DJ, Clark PM, et al. (1991) Fetal and infant growth and impaired glucose tolerance at age 64. BMJ 303, 1019-1022.

44. Robinson SM \& Barker DJ (2002) Coronary heart disease: a disorder of growth. Proc Nutr Soc 61, 537-542.

45. Barker DJ, Osmond C, Forsen TJ, et al. (2005) Trajectories of growth among children who have coronary events as adults. $N$ Engl J Med 353, 1802-1809.

46. MacLennan WJ, Hamilton JC \& Darmady JM (1980) The effects of season and stage of pregnancy on plasma 25-hydroxy-vitamin D concentrations in pregnant women. Postgrad Med J 56, 75-79.

47. Martinez ME, Salinas M, Navarro MP, et al. (1986) The effects of season and stage of pregnancy on 25-hydroxy-vitamin D levels in pregnant women in Madrid. Int J Vitam Nutr Res 56, $131-134$. 